
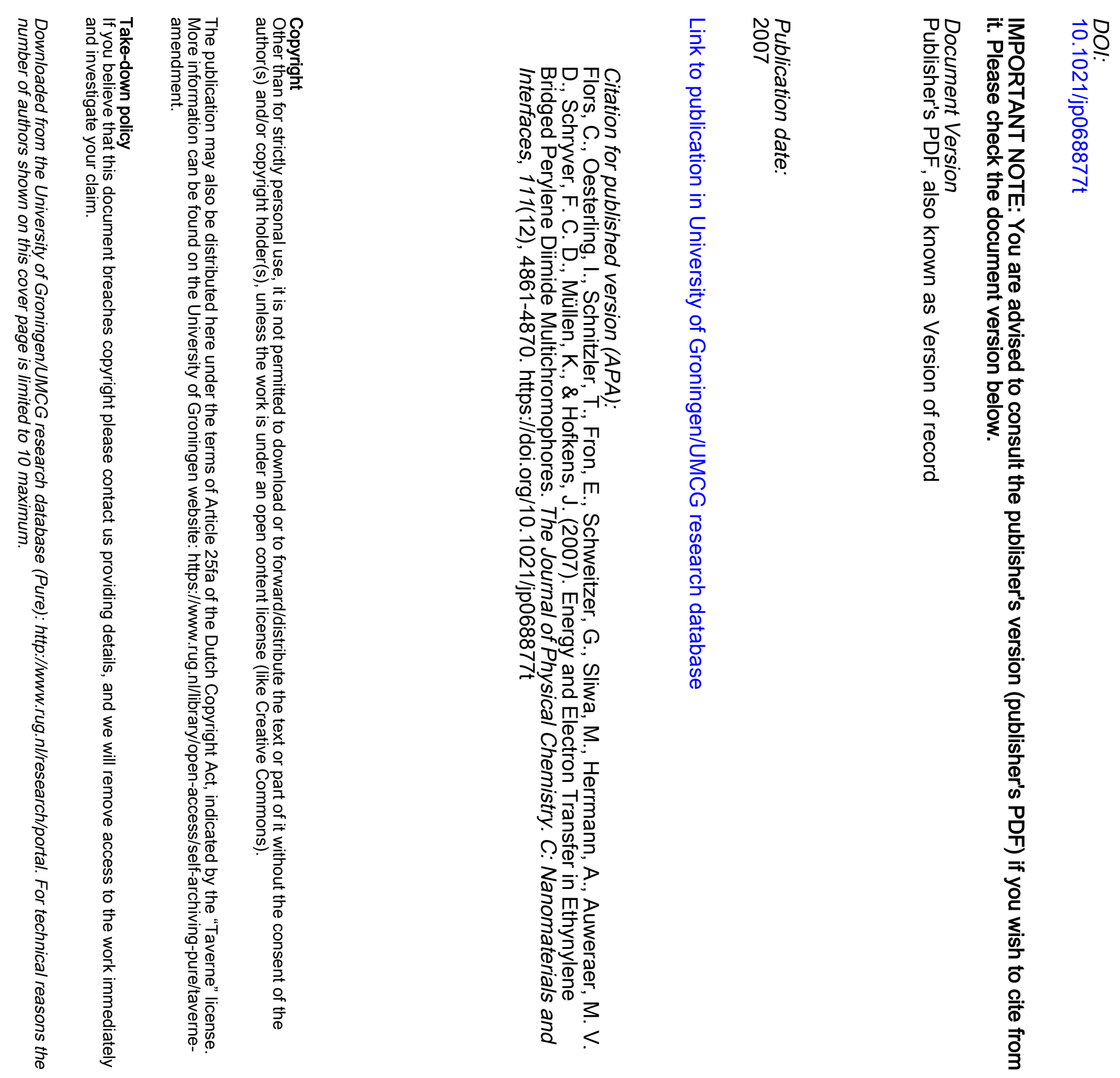

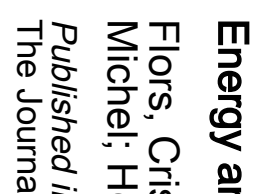

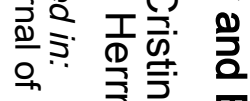

艾 总

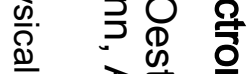

음

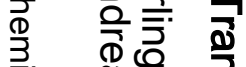

क

긍

z $\sum_{0}$

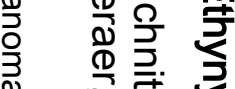

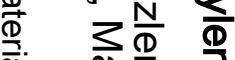

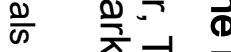

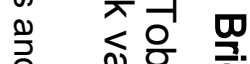

专 흥

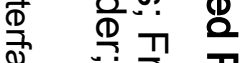

๙

紧

ญ

응

क ल

$\Omega \underset{\Phi}{\mathbb{D}}$

음 중

उo

호응 응

즈에

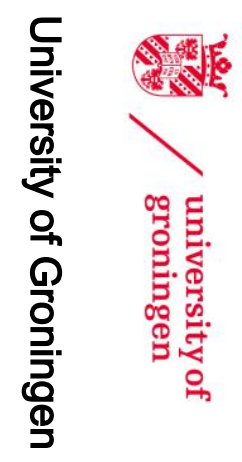




\title{
Energy and Electron Transfer in Ethynylene Bridged Perylene Diimide Multichromophores
}

\author{
Cristina Flors, ${ }^{\dagger}$ Ingo Oesterling, ${ }^{\ddagger}$ Tobias Schnitzler, ${ }^{\ddagger}$ Eduard Fron, ${ }^{\dagger}$ Gerd Schweitzer, ${ }^{\dagger}$ \\ Michel Sliwa, ${ }^{\dagger}$ Andreas Herrmann, ${ }^{\ddagger}$ Mark van der Auweraer, ${ }^{\dagger}$ Frans C. de Schryver ${ }^{\dagger}$ \\ Klaus Miillen, $* \star \star ;$ and Johan Hofkens $*, \dagger$ \\ Department of Chemistry and Institute for Nanoscale Physics and Chemistry (INPAC), Katholieke Universiteit \\ Leuven, Celestijnenlaan 200F, B-3001 Heverlee, Belgium, and Max-Planck-Institut für Polymerforschung, \\ Ackermannweg 10, D-55128 Mainz, Germany
}

Received: December 22, 2006

\begin{abstract}
Shape persistent perylene diimide (PDI) multichromophores incorporating ethynylene bridges have been synthesized in high yield via palladium-catalyzed Hagihara coupling, which provides compounds with no rotational or constitutional isomerism in contrast to polyphenylene dendrimers. Their excited-state pathways have been studied at the ensemble and at the single-molecule level and compared to several model compounds. In an apolar solvent, energy hopping and/or energy transfer between the chromophoric units are the dominating processes. In a polar medium, energy hopping is still operative, but electron transfer from the phenyl ethynylene bridge to the chromophore occurs if the former is connected to the bay area of PDI. This effect should be considered when further developing this type of multichromophore, as this nonradiative deactivation process might be unwanted for applications such as optical and electronic devices. At the single-molecule level, the fluorescence intensity traces are characterized by rich on-off dynamics, which we attribute to oxygen-enhanced intersystem crossing leading to the formation of a long-lived dark charge-separated state.
\end{abstract}

\section{Introduction}

The study of energy dissipation pathways in supramolecular organizations of chromophoric units is relevant for the development of photonic devices ${ }^{1,2}$ and for the understanding of photobiological processes such as photosynthesis or energy transfer in oligomeric autofluorescent proteins. ${ }^{3,4}$ Insight into chromophore-chromophore interactions can be gained by studying model systems in which a few preconditions are required. The system should have a discrete number of chromophores that are in a well-defined geometrical relationship to each other, and the chromophores themselves should exhibit a high efficiency of absorption and emission. Rylene dyes fulfill the chromophore requirements, because they are characterized by excellent photochemical stability as well as high fluorescence, high extinction coefficients, and high fluorescent quantum yields (refs 5 and 6 and references therein), which make them ideal candidates for single-molecule studies. ${ }^{7,8}$ One group of rylene chromophores are perylene diimides (PDIs, Figure 1), which are widely used in functional multichromophoric architectures. ${ }^{5,6,9-12}$ At the single-molecule level, PDI-based systems have been used to study, among others, photoinduced electron-transfer processes ${ }^{13-17}$ because of their moderate oxidation and reduction potentials. ${ }^{18,19}$ Energy transfer and energy hopping processes leading to efficient single photon emission have also been shown to occur in such systems, ${ }^{20}$ and PDIs have also been incorporated into so-called photonic wires for their study at the single-molecule level. ${ }^{21}$

Dendrimers with polyphenylene branches have been used to ensure the well-defined spatial relationship between its PDI

\footnotetext{
* To whom correspondence should be addressed johan.hofkens@chem.kuleuven.be (J.H.) and muellen@mpip-mainz.mpg.de (K.M.).

$\doteqdot$ Katholieke Universiteit Leuven.

Max-Planck-Institut für Polymerforschung.
}

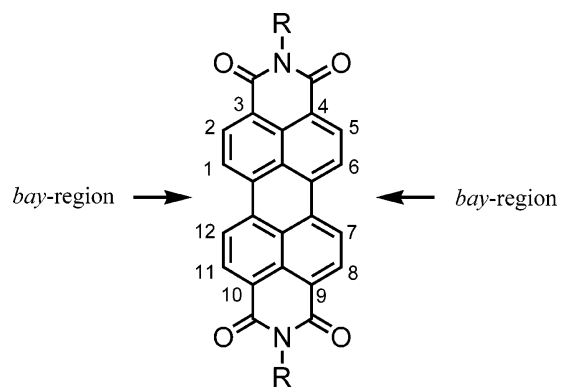

Figure 1. Chemical structures of perylene-3,4:9,10-tetracarboxdiimide (PDI).

substituents because of their shape persistence. ${ }^{6,22,23}$ However, the synthesis of chromophore-substituted polyphenylene dendrimers suffers from a few drawbacks. Tedious syntheses of the chromophore-substituted tetraphenylcyclopentadienone building blocks are often required, leading to low overall yields. Furthermore, when using a tetraphenylcyclopentadienone building block without $C_{2}$ symmetry, a statistical distribution of constitutional isomers of the resulting polyphenylene dendrimers is formed owing to the mechanism of the Diels-Alder cycloaddition. $^{22}$ This results in ambiguities of the interchromophore distances, which must be considered in single-molecule spectroscopic examinations. Figure 2 shows two of the five possible constitutional isomers for a polyphenylene dendrimer with four chromophores on the periphery for which the difference in distance becomes evident. With the chromophores not linked in the para position of the outer phenyl rings, as in Figure 2A, but linked in the meta position (B), rotational isomers also come into play, further increasing the number of inter-chromophore distances (for a detailed discussion on the effects of isomerism on the photophysical behavior of polyphenylene dendrimers see refs 24 and 25). 

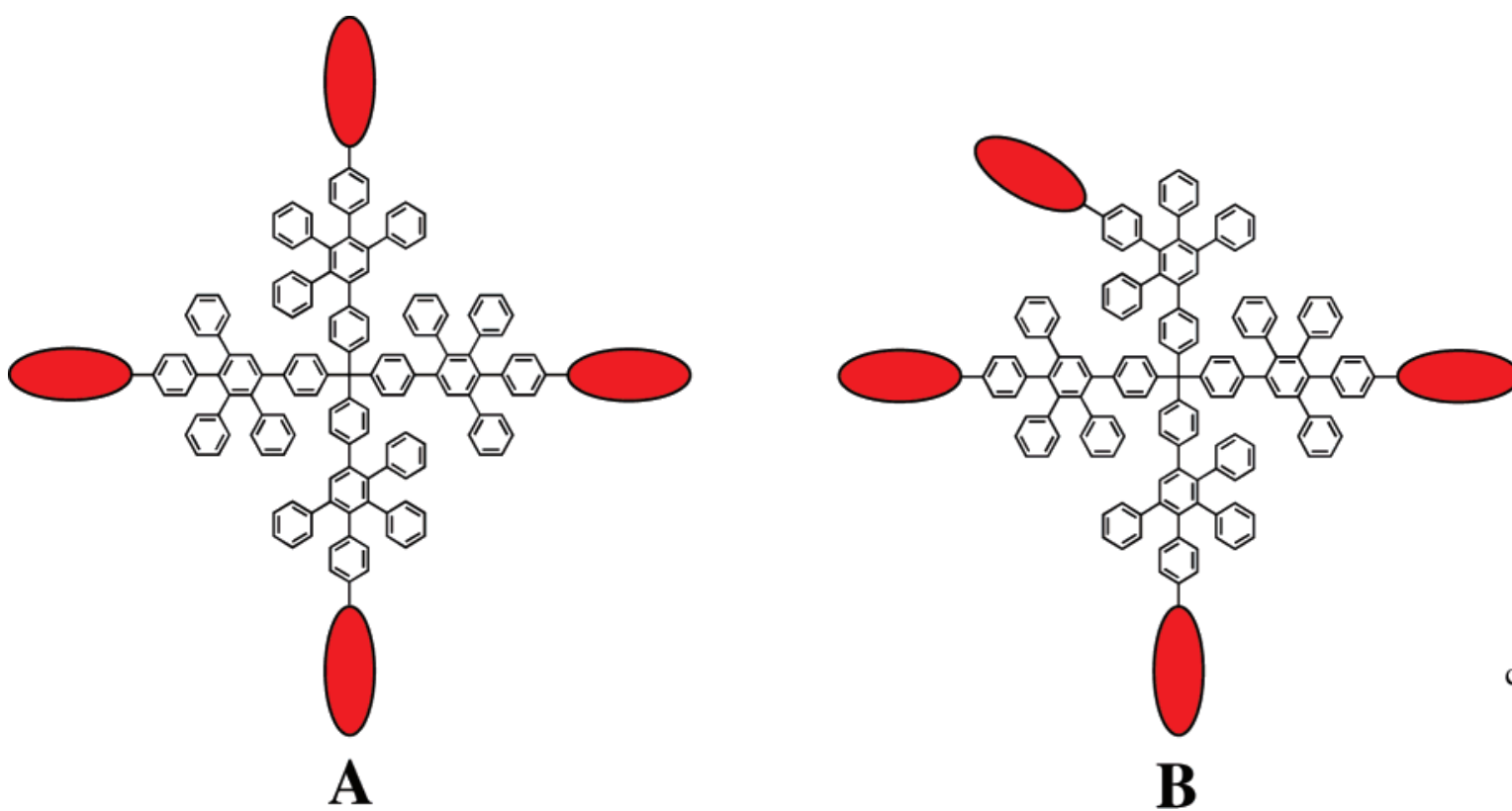

Figure 2. Two of five possible constitution isomers of a polyphenylene dendrimer with four chromophores at the periphery.
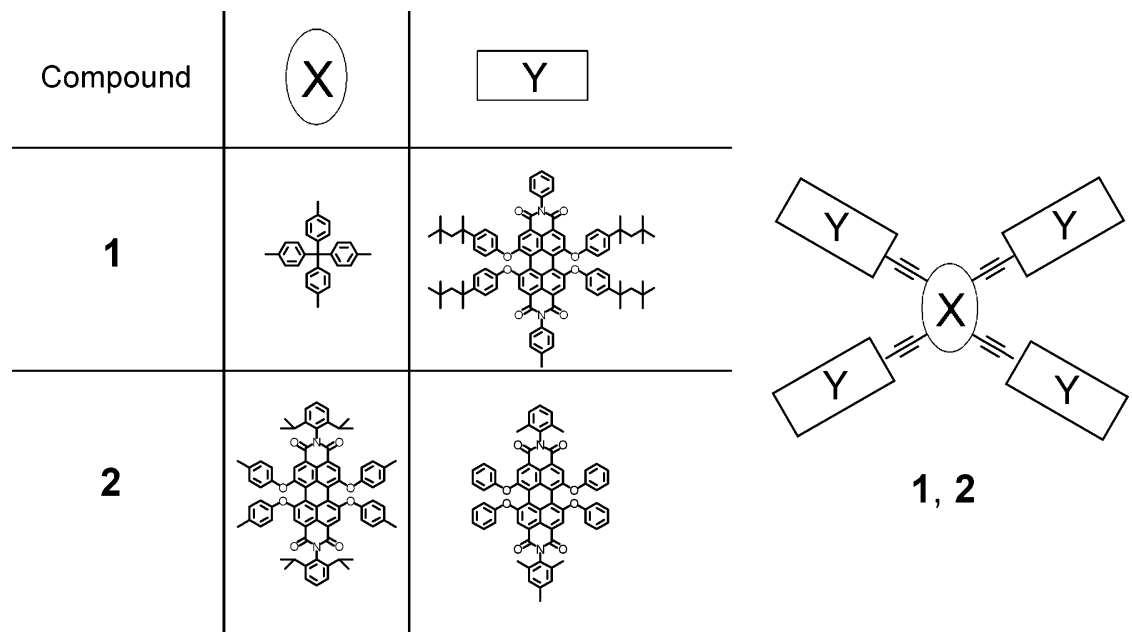

1,2

chromophore

Figure 3. Multichromophores 1 and 2.

In this paper we present a new route to incorporate highly fluorescent PDI chromophores into a well-defined spatial arrangement within multichromophoric systems. In these systems the single fluorophores are connected to a core molecule via an ethynylene bridge (see Figure 3), whereby the palladiumcatalyzed Hagihara coupling between an arylhalogen and a terminal alkyne ${ }^{26,27}$ serves as basis for the buildup of these ethynylene bridges. As this synthetic concept is distinguished by a simple accomplishment of the reaction and high overall yields, it was already successfully applied for the buildup of multichromophores, based on the linkage of phenylacetylenes. ${ }^{28-30}$ Like the polyphenylene dendrimers, these multichromophores are shape persistent, and therefore, the functions at the periphery are in a topological defined location. Using this synthetic strategy, the two multichromophores $\mathbf{1}$ and $\mathbf{2}$ (Figure 3) are synthesized via a palladium-catalyzed Hagihara reaction. Each multichromophore carries four peripheral PDI chromophores linked by an ethynylene bridge to a core unit. None of the new chromophores give rise to rotational and/or constitutional isomerism.

We have undertaken the photophysical study of the multichromophores in Figure 3 by ensemble spectroscopy to elucidate the possible influence of the ethynylene functions on the excited-
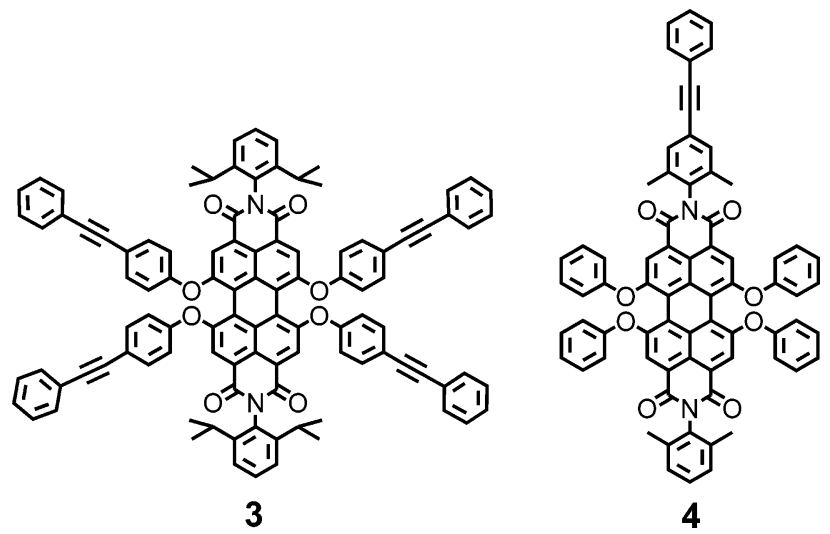

Figure 4. Chemical structures of the model compounds 3 and 4.

state properties of the chromophores. We have also synthesized and investigated the model compounds 3 and $\mathbf{4}$ (Figure 4), which symbolize the core unit of $\mathbf{2}$ and the peripheral chromophores of both multichromophores, respectively. Electrochemical and some single-molecule measurements have been performed to complement the ensemble spectroscopical investigation. Our results show that energy hopping/transfer processes are operative 
in the multichromophores, but that electron transfer from the ethynylene bridge can interfere.

\section{Experimental Section}

Synthesis. The detailed synthetic procedures and product characterization are available as Supporting Information.

Ensemble and Single-Molecule Spectroscopy. Ensemble steady-state spectra were collected with a Lambda 40 spectrophotometer (Perkin-Elmer) and a Fluorolog 1500 fluorimeter (Spex). Fluorescence quantum yields $\left(\Phi_{\mathrm{F}}\right)$ were measured using cresyl violet in methanol as the reference $\left(\Phi_{\mathrm{F}}=0.55\right),{ }^{31}$ with $\lambda_{\text {ex }}=543 \mathrm{~nm}$. Time-resolved measurements were performed using the time-correlated single photon counting (TCSPC) technique, ${ }^{32}$ with excitation at $543 \mathrm{~nm}(8 \mathrm{MHz}, 1.2 \mathrm{ps}$ full width at half-maximum, fwhm) from the frequency doubled output of an optical parametric oscillator (GWU) pumped by a Ti: sapphire laser (Tsunami, Spectra Physics). A Berek compensator and a polarizer allowed the recording of the fluorescent decays at three different orientations of the emission polarizer, magic angle, parallel $\left(I_{\text {par }}\right)$ and perpendicular $\left(I_{\text {perp }}\right)$, relative to the polarization of the excitation light. The anisotropy decay, $r(t)$, was calculated as

$$
r(t)=\frac{I_{\mathrm{par}}(t)-G I_{\mathrm{perp}}(t)}{I_{\mathrm{par}}(t)+2 G I_{\mathrm{perp}}(t)}
$$

where $G$ is a correction factor that accounts for the different sensitivities in parallel and perpendicular detection (1.7 in our case), and was fitted by a linear combination of exponentially decaying functions (convolution with the IRF was not taken into account). ${ }^{33,34}$ The width of the measured experimental instrument response function was about $50 \mathrm{ps}$.

For single-molecule experiments, the same laser source was used, and the light was directed into an inverted microscope (Olympus IX 70) and focused onto the sample through an oil immersion objective (1.4 NA, $\times 60$, Olympus). Fluorescence was collected through the same objective and split by a $50: 50$ nonpolarizing beam splitter. Half of the detected fluorescence was focused onto a polychromator coupled to a liquid nitrogencooled charge-coupled device (CCD) camera (LN/CCD-512SB, Princeton Instruments), and the other half was sent to an avalanche photodiode (SPCM 15, EG\&G). In some cases, the latter fluorescence was again split with a polarizing beam splitter (50:50) and sent to two different avalanche photodiodes detecting polarization directions perpendicular to each other. Time-resolved data were collected with a TCSPC card (SPC 630, Becker \& Hickl) operated in First-in-fist-out mode. The detailed description of the setup and the data acquisition process has been published previously. ${ }^{24}$

The femtosecond transient absorption experiments were performed with an amplified femtosecond double OPA laser system as described previously. ${ }^{35}$ Briefly, the femtosecond pulses coming from a regeneratively amplified (RGA, Spitfire, Spectra Physics) Ti:sapphire laser (Tsunami, Spectra Physics) were used to pump an optical parametric amplifier (OPA 800II, Spectra Physics), which was tuned at $580 \mathrm{~nm}$ (300 fs fwhm). A small fraction of the RGA light was used to generate a white light continuum in a sapphire plate, which then served as the probe light. The detection was done by a CCD camera (EEV 30, Princeton Instruments) mounted at the exit of a spectrograph (SP300i, Acton Research). The transient absorption spectra were recorded for 512 delay positions in time windows of 420 ps and $3 \mathrm{~ns}$. The sample was in a quartz cuvette (1 mm path) and was probed at $54.8^{\circ}$ relative to the pump light polarization plane.
Ensemble measurements were mostly performed with airsaturated samples, because degassing did not affect the results significantly. Samples for single-molecule experiments were prepared by spin-casting about $10^{-10} \mathrm{M}$ solutions of the compounds in chloroform containing $6 \mathrm{mg} / \mathrm{mL}$ polymethylmethacrylate (PMMA) polymer onto thoroughly cleaned glass coverslips. Single-molecule measurements were performed with typical excitation power at the sample of about $2 \mathrm{~kW} / \mathrm{cm}^{2}$. Toluene (Acros) and tetrahydrofuran (THF, Aldrich) were of spectroscopical quality. PMMA (Aldrich, $M_{\mathrm{w}} \approx 93000$ ) was used without further purification.

Electrochemical measurements were carried out with an EG\&G model 173 potentiostat. The solvent used was $\mathrm{CH}_{2} \mathrm{Cl}_{2}$ (water free, purchased from Aldrich) containing 0.1 M TBA$\mathrm{ClO}_{4}$. The electrochemical cell was fitted with a $1.0 \mathrm{~mm}$ diameter platinum disk working electrode and a platinum wire counter electrode. A silver wire served as quasi-reference electrode. The ferrocene/ferrocinium redox couple $\left(\mathrm{Fc} / \mathrm{Fc}^{+}, 0.45\right.$ $\mathrm{V})$ is used as an internal reference. The normal scanning rate was $100 \mathrm{mV} / \mathrm{s}$. All experiments were performed under dry, oxygen-free nitrogen, at room temperature.

\section{Results and Discussion}

Synthesis. Multichromophore 1. 1,6,7,12-Tetrachloroperylene3,4:9,10-tetracarboxdianhydride $(5)^{36}$ was reacted with aniline (6) and 4-iodoaniline (7) in propanoic acid for $16 \mathrm{~h}$ at $150{ }^{\circ} \mathrm{C}$ leading to a statistic product mixture comprising $\mathbf{8}$ as one of the byproducts. As a result of the low solubility of the product mixture in common organic solvents, a separation of $\mathbf{8}$ was not achieved. The crude product was used directly after precipitation from water, without further purification. After the subsequent substitution of the chlorides with an excess of phenol (9) in $N$-methylpyrrolidone (NMP) at $90{ }^{\circ} \mathrm{C}$, the product was purified by column chromatography as a result of its increased solubility. PDI-chromophore $\mathbf{1 0}$ was obtained as a red solid in 25\% yield. The multichromophore $\mathbf{1}$ was synthesized in a $\mathrm{Pd}(0)$-mediated Hagihara coupling reaction ${ }^{27}$ with $\mathbf{1 0}$ and the tetrahedral core molecule tetrakis(4-ethynylphenyl)methane (11). The reaction was carried out in $\mathrm{THF} /$ triethylamine at room temperature with a $\left[\mathrm{PdCl}_{2}\left(\mathrm{PPh}_{3}\right)_{2}\right] / \mathrm{CuI}$ catalyst system. Column chromatography with $\mathrm{CH}_{2} \mathrm{Cl}_{2}$ as the eluent afforded the multichromophore $\mathbf{1}$, bearing four PDI chromophores substituted around a tetraphenylmethane core molecule in $72 \%$ yield. The synthesis of compound $\mathbf{1}$ is shown in Scheme 1.

Multichromophore 2 and Model Compound 3. Using the same synthetic strategy for the monofunctionalization of a PDI chromophore via a statistic imidization, PDI-chromophore $\mathbf{1 5}$ was synthesized in a two-step reaction (Scheme 2). First, a statistical imidization of 1,6,7,12-tetrachloroperylene-3,4:9,10tetracaboxdianhydride (5) with 2,6-dimethylaniline (12) and 4-bromo-2,6-dimethylaniline (13) was performed. Afterward, the crude product was used in a phenoxylation reaction with an excess of phenol (14). Column chromatography gave PDI chromophore 15 in $22 \%$ yield. A subsequent Hagihara coupling with triisopropylsilylacetylene (16) afforded 17 in 65\% yield. The removal of the protecting group was obtained with tetrabutylammonium fluoride in nearly quantitative yields, leading to the ethynyl-functionalized chromophore 18. In a final Hagihara reaction (Scheme 3), 18 was coupled with the fourfold iodo-functionalized PDI-chromophore $\mathbf{1 9}^{37}$ to achieve the multichromophore 2, bearing four PDI-chromophores substituted around one central PDI chromophore.

To obtain a model compound of the central PDI chromophore, 19 was treated with phenylacetylene (20) to afford 3 carrying 
SCHEME 1: Synthesis of the Multichromophore $1^{a}$

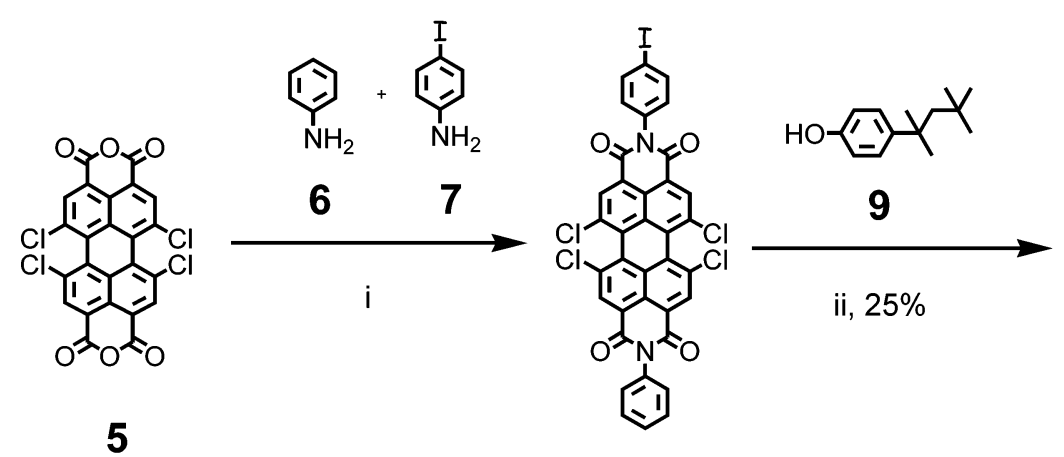

8

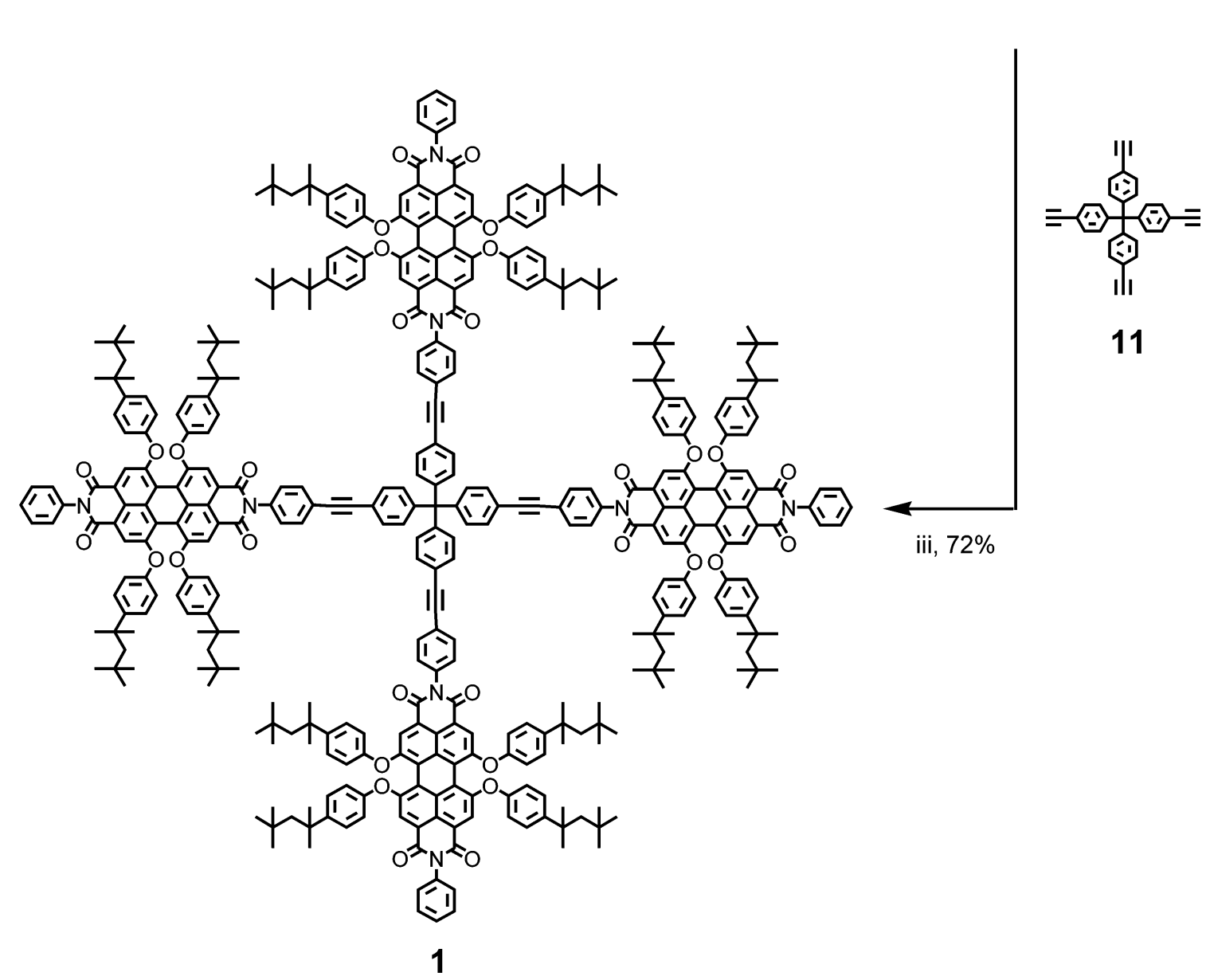

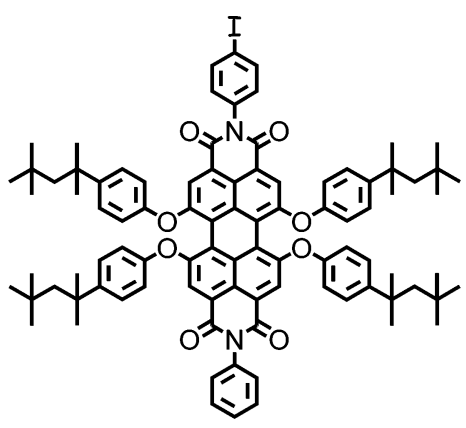

10

${ }^{a}$ (i) Aniline (6), 4-iodoaniline (7), propionic acid, $16 \mathrm{~h}, 150{ }^{\circ} \mathrm{C}$. (ii) $4-\left(1^{\prime}, 1^{\prime}, 3^{\prime}, 3^{\prime}-\right.$ Tetramethylbutyl)phenol (9), $\mathrm{K}_{2} \mathrm{CO}_{3}, \mathrm{NMP}, 64 \mathrm{~h}, 90{ }^{\circ} \mathrm{C}, 25 \%$. (iii) Tetra(4-ethynylphenyl)methane (11), $\mathrm{CuI}, \mathrm{PPh}_{3}$; $\left[\mathrm{Pd}\left(\mathrm{PPh}_{3}\right) \mathrm{Cl}_{2}\right], \mathrm{THF} /$ triethylamine $(1 / 3), 16 \mathrm{~h}, 40{ }^{\circ} \mathrm{C}, 72 \%$.

four phenyl-substituted alkynes in the bay region of the chromophore in $68 \%$ yield (Scheme 3 ).

Model Compound 4. For a model compound of the chromophores of the periphery, each bearing a phenyl-substituted ethynyl group in the imide structure, PDI-chromophore 4 was synthesized (Scheme 4). A direct conversion of the bromofunctionalized PDI 15 to 4 with phenylacetylene (20) was unsuccessful, possibly because of the deactivating influence of the imide structure on the bromine atom. As iodo functions are known to be much more reactive in Hagihara coupling reactions, ${ }^{30,38}$ the PDI-chromophore $\mathbf{2 3}$ was prepared, bearing an iodo instead of the bromo function in the imide structure. The same strategy of statistic imidization (this time with 4-iodo2,6-dimethylaniline (21) instead of 13) with subsequent phenoxylation as aforementioned was used. Column chromatography gave 22 in $16 \%$ yield. In the final step, 23 was coupled with phenylacetylene (20) in a microwave reactor for $12 \mathrm{~h}$ at $125 \mathrm{~W}$ and $125^{\circ} \mathrm{C}$. Column chromatography gave the model compound 4 in $45 \%$ yield.

Photophysical and Electrochemical Properties. SteadyState Measurements. The normalized absorption and emission spectra of 1-4 in toluene are shown in Figure 5 (see Figure $\mathrm{S} 1$, Supporting Information, for THF), and their photophysical properties in toluene and THF are summarized in Table 1. The maximum of the spectra for all compounds is very similar. Both absorption and fluorescence spectra are slightly shifted to the blue in THF as compared to toluene, which we can attribute to the stabilizing effect of the higher polarizability of toluene. The shape of the fluorescence spectrum remained the same in both solvents, indicating that all fluorescence arises from the locally excited state. The values of $\Phi_{\mathrm{F}}$ are all close to unity in toluene. However, in the more polar THF there are significant differences 
SCHEME 2: Synthesis of the Ethynyl-Functionalized PDI-Multichromophore $18^{a}$

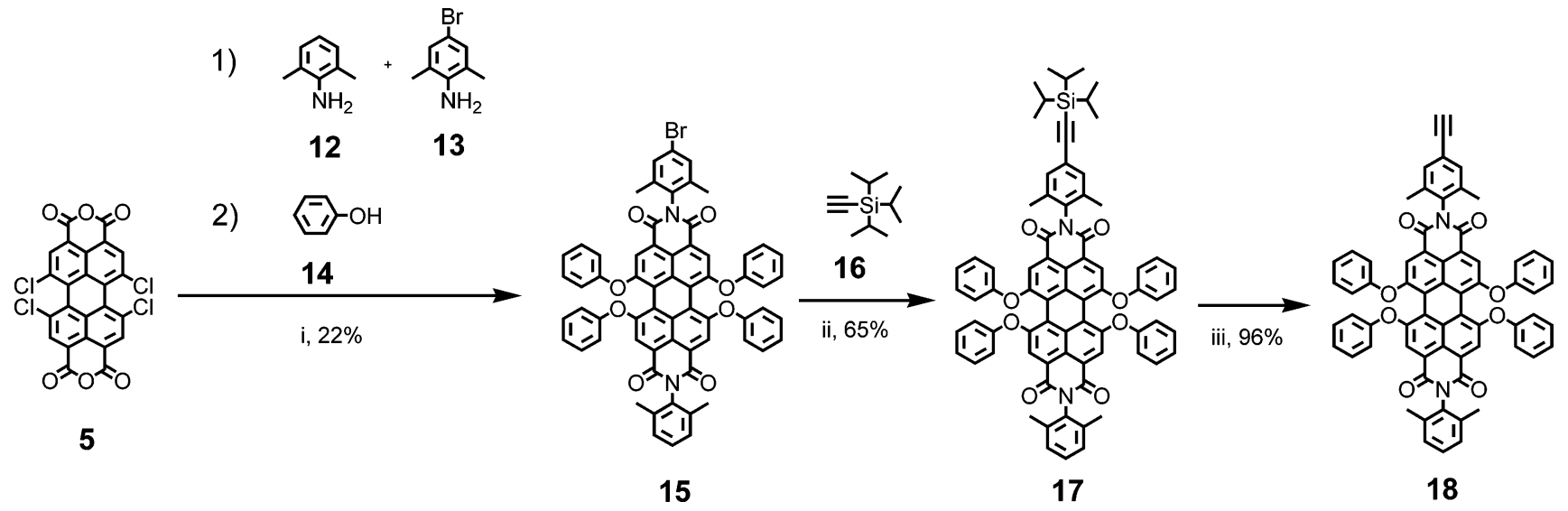

${ }^{a}$ (i) (1) 2,6-Dimethylaniline (12), 4-bromo-2,6-dimetylaniline (13), propionic acid, $16 \mathrm{~h}, 150{ }^{\circ} \mathrm{C}$; (2) phenol (14), $\mathrm{K}_{2} \mathrm{CO}_{3}, \mathrm{NMP}, 16 \mathrm{~h}, 90{ }^{\circ} \mathrm{C}$, $22 \%$. (ii) Tri-isopropylsilylacetylene (16), CuI, $\mathrm{PPh}_{3}$; $\left[\mathrm{Pd}\left(\mathrm{PPh}_{3}\right) \mathrm{Cl}_{2}\right], \mathrm{THF} /$ triethylamine $(1 / 2), 16 \mathrm{~h}, 80{ }^{\circ} \mathrm{C}, 65 \%$. (iii) Tetrabutylammonium fluoride, THF, 1 h, 96\%.

SCHEME 3: Synthesis of the Multichromophore 2 and the Model Compound 3, Bearing Phenylethynyl Groups in the Bay Region of the Chromophore ${ }^{a}$

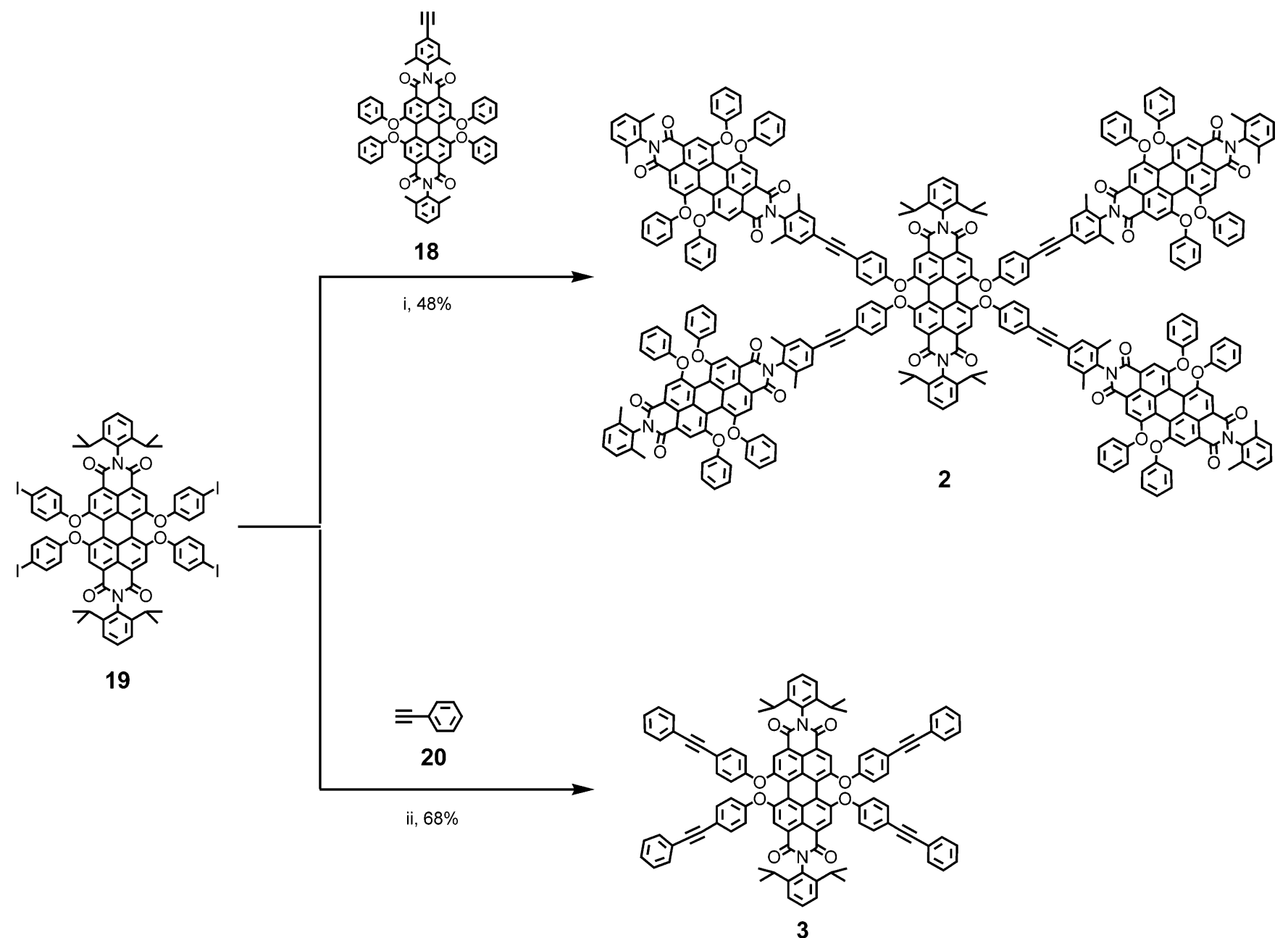

${ }^{a}$ (i) PDI-chromophore 18, CuI, $\mathrm{PPh}_{3} ;\left[\mathrm{Pd}\left(\mathrm{PPh}_{3}\right) \mathrm{Cl}_{2}\right]$, THF/triethylamine (1/2), 16 h, rt, 48\%. (ii) Phenylacetylene $(\mathbf{2 0}), \mathrm{CuI}, \mathrm{PPh}_{3} ;\left[\mathrm{Pd}\left(\mathrm{PPh}_{3}\right) \mathrm{Cl}{ }_{2}\right]$, THF/triethylamine (2.5/1), 16 h, rt, 68\%. (iii) Tetrabutylammonium fluoride, THF, $1 \mathrm{~h}, 96 \%$.

among the compounds: $\mathbf{1}$ and $\mathbf{4}$ show a similar unity value as in toluene, whereas $\Phi_{\mathrm{F}}$ drops for $\mathbf{2}$ and $\mathbf{3}$. The latter observation indicates the appearance of radiationless deactivation channels that are favored when the solvent polarity is increased, electron transfer being the most likely candidate (see below). The appearance of such deactivation channels in THF seems to be connected to the presence of a diphenylacetylene group in the bay area of PDI (as in compounds 2 and $\mathbf{3}$ ) but seems to be absent when the same group is bound to the imide nitrogen (as in compounds $\mathbf{1}$ and $\mathbf{4}$ ).

TCSPC Experiments. Fluorescence lifetime values (Table 1, Figure 6) indicate a similar trend as outlined above for the quantum yield of fluorescence. All compounds in toluene, and also 1 and 4 in THF, decay with a lifetime between 5 and $6 \mathrm{ns,}$ 
SCHEME 4: Synthesis of the Model Compound 4, Bearing a Phenylethynyl Group in the Imide Structure ${ }^{a}$

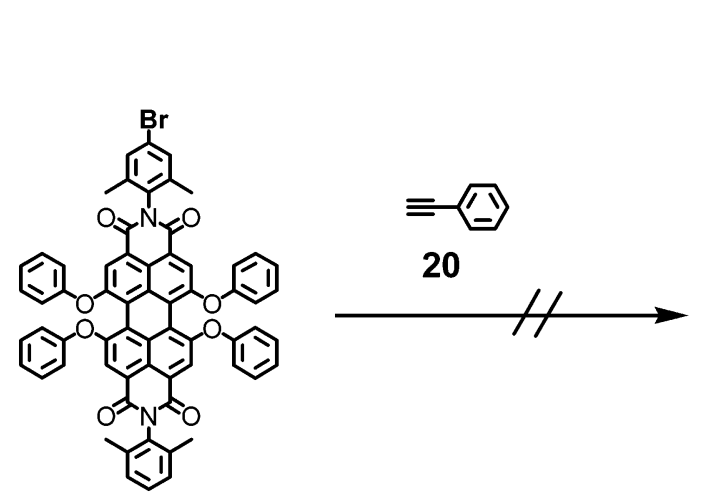

15

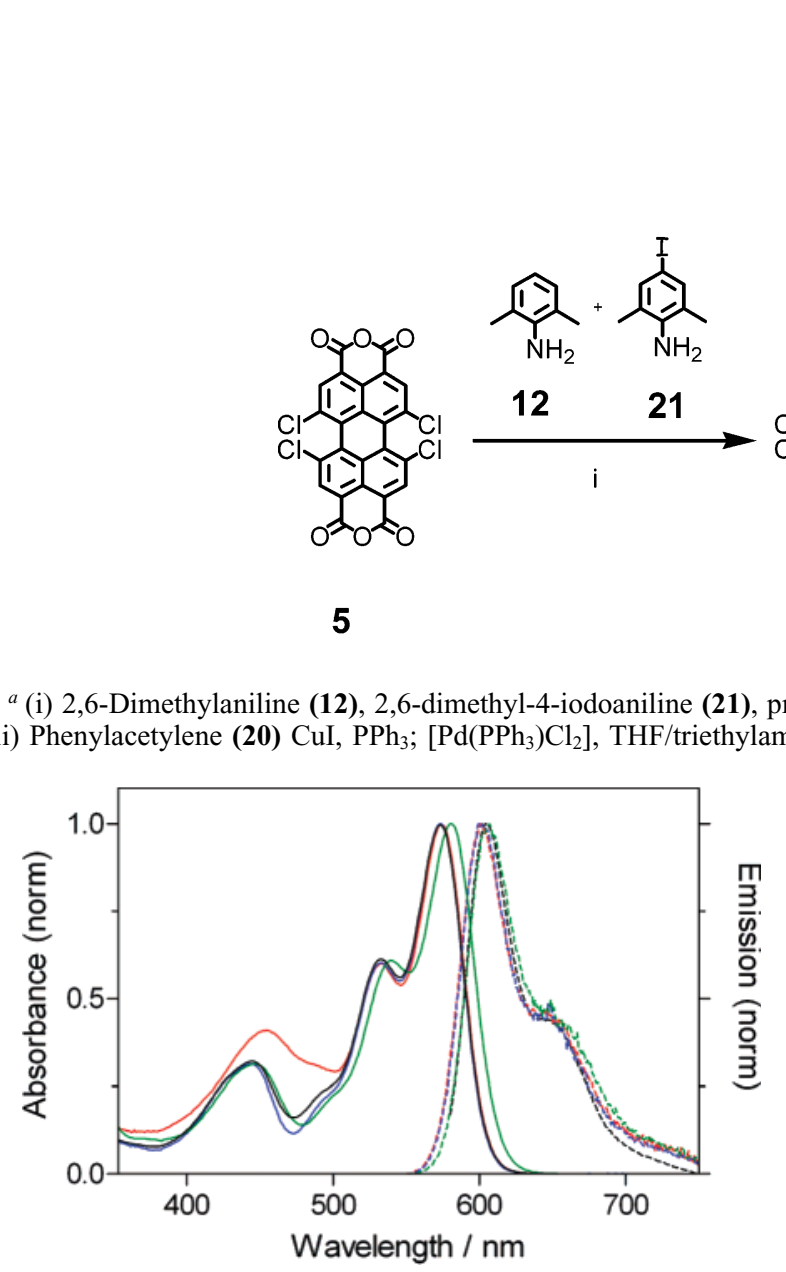

Figure 5. Normalized absorption (solid line) and emission (dotted line) of 1 (green), 2 (black), 3 (red), and 4 (blue) in toluene.

typical for unquenched PDI compounds. Compound 3 in toluene shows an additional small (7\% relative amplitude) rise in the subnanosecond range, which we tentatively attribute to a rather slow conformational change due to a decreased conformational mobility of the substituents in the bay area. This small rise is absent in 2, probably because of fast energy hopping/transfer processes (see below). The situation is rather different for $\mathbf{2}$ and $\mathbf{3}$ in THF: compound $\mathbf{3}$ decays monoexponentially with a lifetime of $1.1 \mathrm{~ns}$, and the multichromophore $\mathbf{2}$ shows a biexponential decay with decay times of 2.8 and $1.0 \mathrm{~ns}$, the latter being close to the lifetime of $\mathbf{3}$ in THF. The contribution of each component approaches the ratio of peripheral versus

22

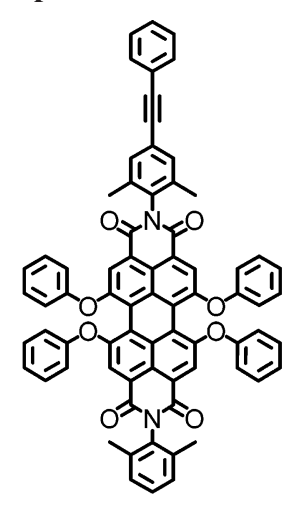

4

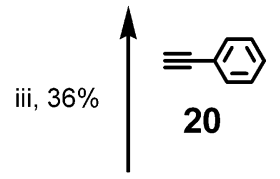

${ }^{a}$ (i) 2,6-Dimethylaniline (12), 2,6-dimethyl-4-iodoaniline (21), propionic acid, $16 \mathrm{~h}, 150{ }^{\circ} \mathrm{C}$. (ii) Phenol (14), $\mathrm{K}_{2} \mathrm{CO}_{3}, \mathrm{NMP}, 16 \mathrm{~h}, 90{ }^{\circ} \mathrm{C}, 16 \%$.

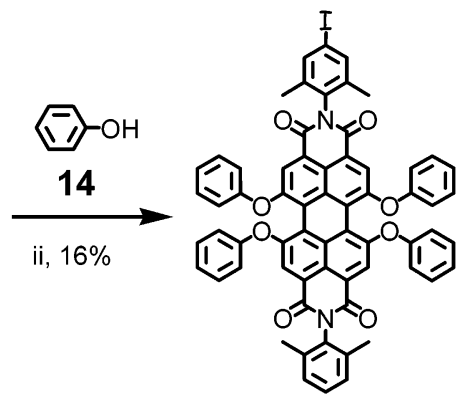

23

(iii) Phenylacetylene (20) $\mathrm{CuI}, \mathrm{PPh}_{3} ;\left[\mathrm{Pd}\left(\mathrm{PPh}_{3}\right) \mathrm{Cl}_{2}\right]$, THF/triethylamine $(2 / 3)$, microwave reactor, $12 \mathrm{~h}, 125 \mathrm{~W}, 125{ }^{\circ} \mathrm{C}, 36 \%$.

central PDIs, strongly supporting the attribution of the long and short lifetimes to the peripheral and the central units, respectively. The shorter decay of 2.8 ns of the peripheral PDIs in 2 as compared to the $5.6 \mathrm{~ns}$ of $\mathbf{1}$ and $\mathbf{4}$ seems to suggest that the oxygen from the phenoxy group, present in $\mathbf{2}$ but not in $\mathbf{1}$ or $\mathbf{4}$, might allow quenching by through-space electron transfer as the electron donating ability of the phenylacetylene group is increased. In any case, the fluorescence decay times of the multichromophores and model compounds show once again that the central PDI unit is the one most affected by quenching from the ethynylene bridges.

As in similar multichromophoric dendrimers, ${ }^{34,39-41}$ energy hopping between the peripheral PDIs or energy transfer between peripheral and central units might occur. To verify that such processes are operative in these new architectures, anisotropy decays were measured and analyzed (Table 1, inset of Figure 6). The monoexponential anisotropy decay time of the model compound 3 in toluene and THF of around $0.4-0.6 \mathrm{~ns}$ can be attributed to rotational diffusion. The values of $\beta$ in both solvents, close to 0.4 (limiting anisotropy, $r_{0}$ ) indicate that the absorption and emission transition dipole moments are almost parallel, ${ }^{34}$ as found previously in other PDI derivatives. ${ }^{42}$ In $\mathbf{1}$ and 2, similar biexponential decays of the anisotropy are found. The nanosecond component can again be attributed to rotation, while the much faster depolarization process of 50-100 ps can be related to energy hopping/transfer occurring in the system. For compound 2, we regard these values as an average over a 
TABLE 1: Summary of the Photophysical Properties of 1-4 in Solution

\begin{tabular}{|c|c|c|c|c|c|c|c|c|}
\hline & \multicolumn{4}{|c|}{ toluene } & \multicolumn{4}{|c|}{$\mathrm{THF}$} \\
\hline & compound $\mathbf{1}$ & compound 2 & compound $\mathbf{3}$ & compound 4 & compound $\mathbf{1}$ & compound 2 & compound $\mathbf{3}$ & compound 4 \\
\hline$\lambda_{\max }^{\text {abs }}, \mathrm{nm}$ & 579 & 573 & 573 & 573 & 573 & 569 & 568 & 569 \\
\hline$\lambda_{\max }{ }^{\text {emi }}, \mathrm{nm}$ & 606 & 604 & 602 & 602 & 603 & 601 & 601 & 600 \\
\hline$\Phi_{\mathrm{F}}$ & 1.00 & 0.99 & 1.00 & 1.00 & 1.00 & 0.42 & 0.11 & 0.96 \\
\hline$\tau_{\mathrm{F}}, \mathrm{ns}$ & 5.3 & 5.1 & $\begin{array}{l}5.3(93 \%) \\
\sim 0.5(7 \%)^{b}\end{array}$ & 5.3 & 5.6 & $\begin{array}{l}1.0(14 \%) \\
2.8(86 \%)\end{array}$ & 1.1 & 5.6 \\
\hline$\Theta_{1}, \mathrm{~ns}\left(\beta_{1}\right)$ & $1.4(0.02)$ & $3.1(0.05)$ & $0.56(0.36)$ & $a$ & $1.0(0.02)$ & $3.1(0.06)$ & $0.38(0.37)$ & $a$ \\
\hline$\Theta_{2}, \operatorname{ps}\left(\beta_{2}\right)$ & $80(0.12)$ & $110(0.09)$ & $a$ & $a$ & $51(0.28)$ & $53(0.23)$ & & $a$ \\
\hline
\end{tabular}

${ }^{a}$ Not measured. ${ }^{b}$ Negative contribution.

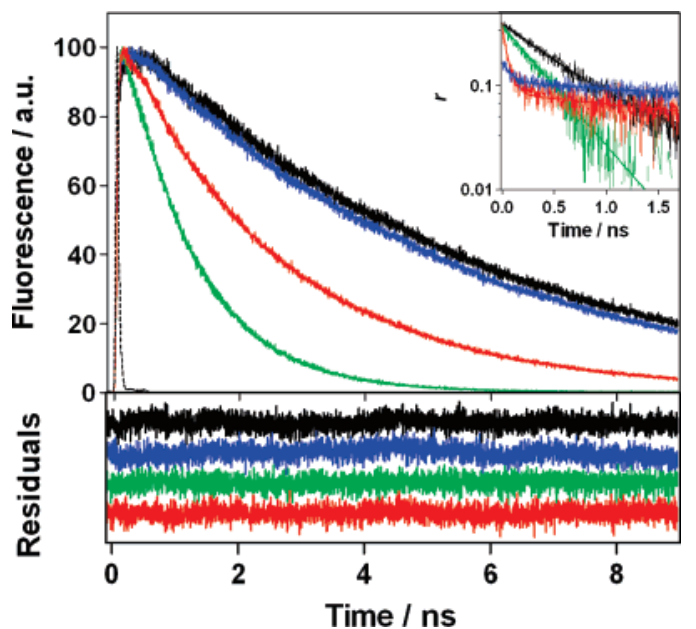

Figure 6. Fluorescence decays, fits, and residuals of $\mathbf{2}$ and $\mathbf{3}$ in toluene (blue and black, respectively) and in THF (red and green, respectively; instrument response function, dotted line). Inset: anisotropy decays.

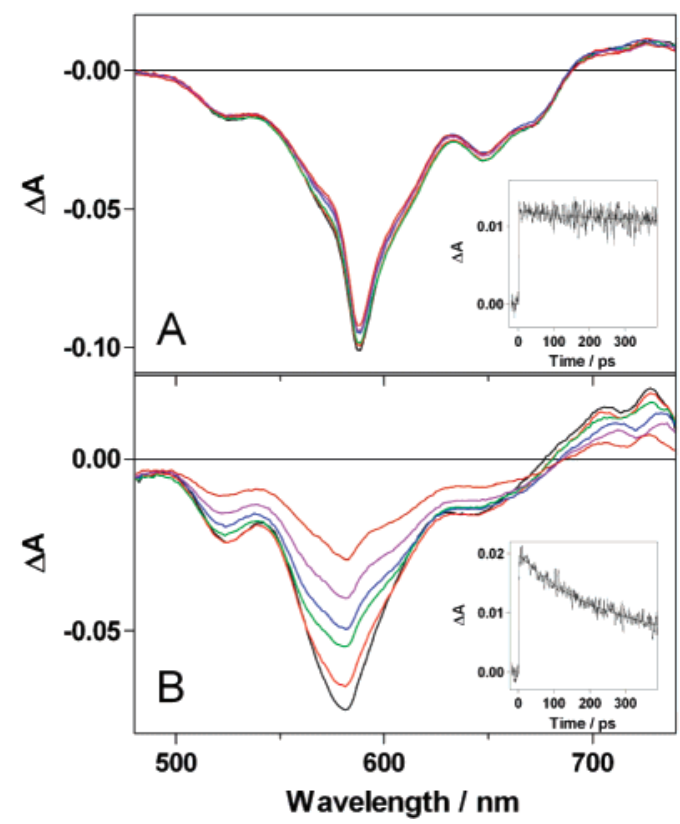

Figure 7. Transient absorption spectra in THF of PDI0 (A) and 3 (B) at 2 (black), 10 (red), 50 (green), 100 (blue), 200 (purple), and 400 ps (brown). Insets: signals and fits at $735 \mathrm{~nm}$.

complex distribution of possible orientations and distances between chromophoric units. By means of the Förster equation, ${ }^{43}$ we have calculated that a 100 ps time constant for hopping corresponds to a distance of about $40 \AA$ (in toluene), which roughly matches the estimated distance between two opposite peripheral PDI units. The faster rates for energy hopping in THF than in toluene can be explained by the dependence of the process on the solvent refractive index $\left(k_{\text {hop }} \sim n^{-4}\right)$. A similar trend has been observed before in other systems as well. ${ }^{40}$ In toluene, the values of $\beta_{1}+\beta_{2}(0.14)$ are smaller than the limiting anisotropy $r_{0}(0.36)$, suggesting the existence of additional, faster processes, which cannot be resolved here because of the limited time resolution of our setup, being most likely energy hopping between neighboring peripheral PDIs and/or transfer between peripheral and central units. Other possibilities that have been suggested in literature for similar systems are the formation of an excimer-like state or singlet-singlet annihilation. ${ }^{40,41,44}$

Femtosecond Transient Absorption Spectroscopy. To confirm the participation of electron-transfer processes from the ethynylene bridge to PDI in THF we performed ultrafast transient absorption spectroscopy on $\mathbf{3}$ (which is the compound that exhibits a more drastic drop in $\Phi_{\mathrm{F}}$, see Table 1). We compared our results with those on the simpler phenoxy-substitued PDI model compound with no diphenyacetylenes, in which no electron transfer is expected to occur $\left(N, N^{\prime}\right.$-diphenyl-1,6,7,12tetrakis[4-(1,1,3,3-tetramethylbutyl)phenoxy]perylene-3,4:9,10tetracarboxdiimide, compound PDI0, Figure S2, Supporting Information). ${ }^{6}$ Both compounds 3 and PDI0 exhibited a broad absorption band at $\lambda>680 \mathrm{~nm}$ (where we expect both the $\mathrm{S}_{1}$ $\rightarrow \mathrm{S}_{n}$ absorption $^{45}$ and the PDI radical anion absorption ${ }^{46,47}$ ), as well as ground state depletion overlapped with the stimulated emission centered at around $580 \mathrm{~nm}$ (Figure 7). The transient absorption of the model compound PDI0 decayed monoexponentially at $\lambda>680 \mathrm{~nm}$, and the decay could be fitted to a lifetime of around $5 \mathrm{~ns}$ (Figure 7). In contrast, the transient absorption of compound $\mathbf{3}$ decayed biexponentially with 185 ps and $1 \mathrm{~ns}$. This biexponential decay suggests that two species that absorb at this wavelength range are present, probably the $\mathrm{S}_{1}$ and the PDI radical anion, and we attribute these lifetimes to the formation and decay, respectively, of the latter species. The absorbance of the phenylacetylene radical cation at $620-$ $630 \mathrm{~nm}^{48}$ is somewhat masked by the ground state depletion and stimulated emission at that wavelength. We found additional fast components ( $<10 \mathrm{ps}$ ) for 3 and PDI0 at $\lambda<680 \mathrm{~nm}$, which we attribute to vibrational/solvent relaxation as found in similar compounds. ${ }^{45,49}$ Thus, we can estimate that the equilibration between the locally excited and the charge-transfer state (characterized by the absorption of the PDI radical anion) occurs with a rate constant as $k_{\mathrm{CT}}=5 \times 10^{9} \mathrm{~s}^{-1}$, which does not fit the value calculated from $\Phi_{\mathrm{F}}$ and the decay time measured by TCSPC $\left(k_{\mathrm{CT}}=9 \times 10^{8} \mathrm{~s}^{-1}\right)$. This indicates that the fluorescence decay obtained by TCSPC corresponds to a more complex kinetics in which the charge-transfer state recombines through $\mathrm{S}_{1}$ in around $1 \mathrm{~ns}$, resulting in delayed fluorescence. A very similar case with comparable photophysical parameters and rate constants has been found for a donor-acceptor pyrene-PDI system. ${ }^{45}$

Measurements on $\mathbf{2}$ in THF yielded similar results as for $\mathbf{3}$ (Figure S3, Supporting Information), that is, a 200 ps component at $\lambda>680 \mathrm{~nm}$ in addition to a component in the $\mathrm{ns}$ range. Such an observation supports the idea that the addition of the 

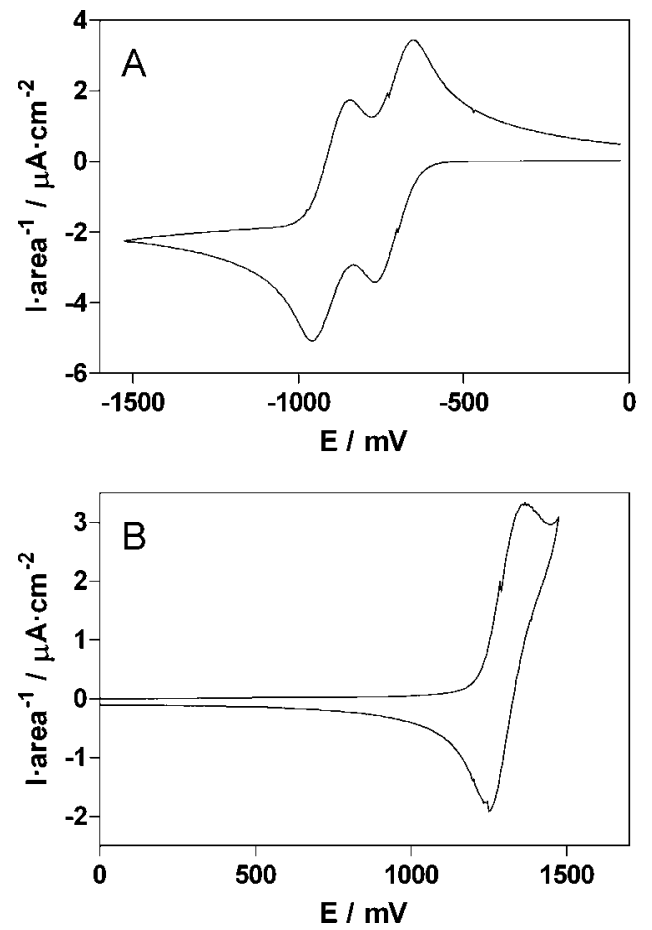

Figure 8. Cyclic voltammograms of 2 in $\mathrm{CH}_{2} \mathrm{Cl}_{2}$ (vs SCE, $100 \mathrm{mV} /$ s): (A) reduction and (B) oxidation.

peripheral PDI units does not influence to a great extent the electron-transfer properties of the core as evidenced by comparing $\mathbf{2}$ and $\mathbf{3}$. Additionally, for $\mathbf{2}$, a faster component of tens of picoseconds is also found at $\lambda>680 \mathrm{~nm}$, which might be related to singlet-singlet annihilation between chromophores.

Electrochemistry. Examining the redox behavior of our compounds can assist in the estimation of the feasibility for photoinduced electron-transfer processes. Reduction of $\mathbf{2}$ in $\mathrm{CH}_{2}-$ $\mathrm{Cl}_{2}$ yields two waves with half-wave potentials of -0.71 and $-0.90 \mathrm{~V}$ versus SCE (Figure $8 \mathrm{~A}$ ), and only one oxidation wave is found at $1.30 \mathrm{~V}$ (Figure $8 \mathrm{~B}$ ), very close to the limit imposed by the solvent used. We attribute the two reduction waves to the incorporation of two consecutive electrons, and the separation between both waves matches very well that found for similar PDI derivatives. ${ }^{18}$ The reduction waves for the central and peripheral PDI units are thus indistinguishable. The relative amplitudes of the reduction and oxidation waves are close to $5: 4$, strongly suggesting that the oxidation wave corresponds to the diphenylacetylene units. The attribution of the oxidation wave to the four peripheral PDI units can be ruled out owing to the identical electrochemical behavior shown in the reduction by all the PDI units in the compound. Similar reduction and oxidation potentials were found for compound 3, although irreversibility was clearly observed even at high scanning rates $(1 \mathrm{~V} / \mathrm{s})$, presumably because of a dimerization reaction taking place in the para position of the outer phenyl ring. ${ }^{50,51}$

From the values of the redox potentials we can estimate the driving force for photoinduced electron transfer in THF and toluene as $-19 \mathrm{~kJ} \cdot \mathrm{mol}^{-1}$ and $+22 \mathrm{~kJ} \cdot \mathrm{mol}^{-1}$, respectively. ${ }^{52}$ Similarly, for the previously studied pyrene-PDI dyad in which delayed fluorescence also occurred, the calculated driving force is $-9 \mathrm{~kJ} \cdot \mathrm{mol}^{-1}$. ${ }^{4}$

Single-Molecule Experiments. At the single-molecule level, the multichromophores display very characteristic traces that are the consequence of competitive energy and electron transfer between its chromophoric units. Figure 9 shows a typical intensity trace of $\mathbf{2}$ in PMMA (with a polarity closer to that of toluene than to that of THF), ${ }^{53}$ recorded in two channels that

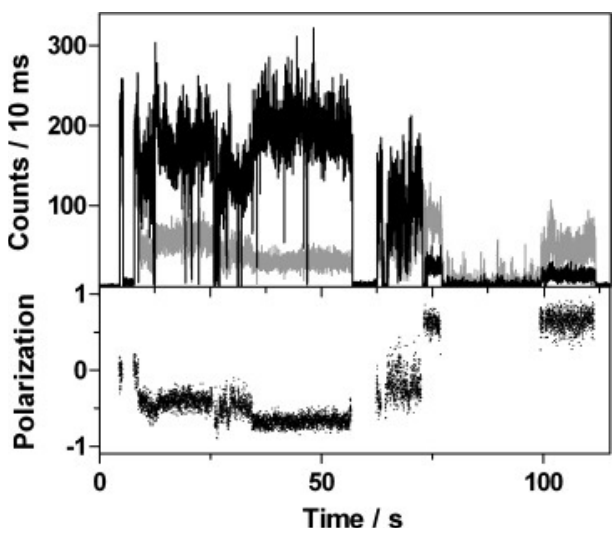

Figure 9. Single-molecule intensity trace and steady-state polarization of 2 in PMMA (air environment) exemplifying energy hopping and on-off blinking. Channels A (gray) and B (black) correspond to polarization directions perpendicular to each other.

detected fluorescence with crossed polarization directions. ${ }^{7}$ The stepwise change in the relative intensity of the channels indicates that the orientation of the emitting chromophore is different; that is, the emitting chromophoric site is changing with time. The change in relative intensity of the two channels is more clearly illustrated by the change in steady-state polarization, defined as

$$
\text { polarization }=\frac{A-G B}{A+G B}
$$

in which $A$ and $B$ are the intensities of the two different channels, and $G$ is a correction factor that accounts for the difference in detection sensitivity in the two channels (calculated as 0.81 in this case). Figure 9 shows several polarization levels, corresponding to different chromophores in $\mathbf{2}$. The change of the emitting chromophoric site in time may be attributed to sequential photobleaching of the chromophores or to temporal stabilization of a certain chromophore by the local environment due to polymer motions. ${ }^{7}$ Besides the different intensity levels, another distinguishing feature of the trace in Figure 9 is that the intensity very frequently drops to background level. The resulting off times last from a few tens of milliseconds to several seconds. These collective off times cannot be explained by excursions to the triplet manifold, because such a state has a lifetime in polymer matrixes of around hundreds of microseconds. $^{20} \mathrm{~A}$ long-lived charge-separated state resulting from electron transfer is the more likely candidate to account for the long-lived blinking behavior. Such blinking at the single-molecule level has already been observed for PDI derivatives and was indeed ascribed to electron transfer related processes..$^{13,15-17}$ In our case, the blinking is frequently observed in the traces of compounds $\mathbf{1}-\mathbf{3}$ but almost absent in $\mathbf{4}$ (Figure 10). This indicates that the possibility of electron transfer between two PDI units or between one PDI and its bay area substituents (as in compound $\mathbf{3}$ ) is necessary for the observation of this blinking. Additionally, we observe a clear effect of oxygen,; that is, blinking is practically suppressed in compounds $\mathbf{1 - 3}$ in the absence of oxygen. Its complex dependence on oxygen and on the feasibility for an intramolecular electron-transfer process suggests that the rich on-off dynamics stem from an oxygenmediated pathway to form a long-lived dark charge-separated state, that is, the enhancement of intersystem crossing from a singlet to a triplet charge-separated state by the presence of the paramagnetic oxygen. ${ }^{54}$ The effect of oxygen on the photophysical pathways at the single-molecule level has been previously reported in a PDI-based system. ${ }^{13}$ It is also worth 

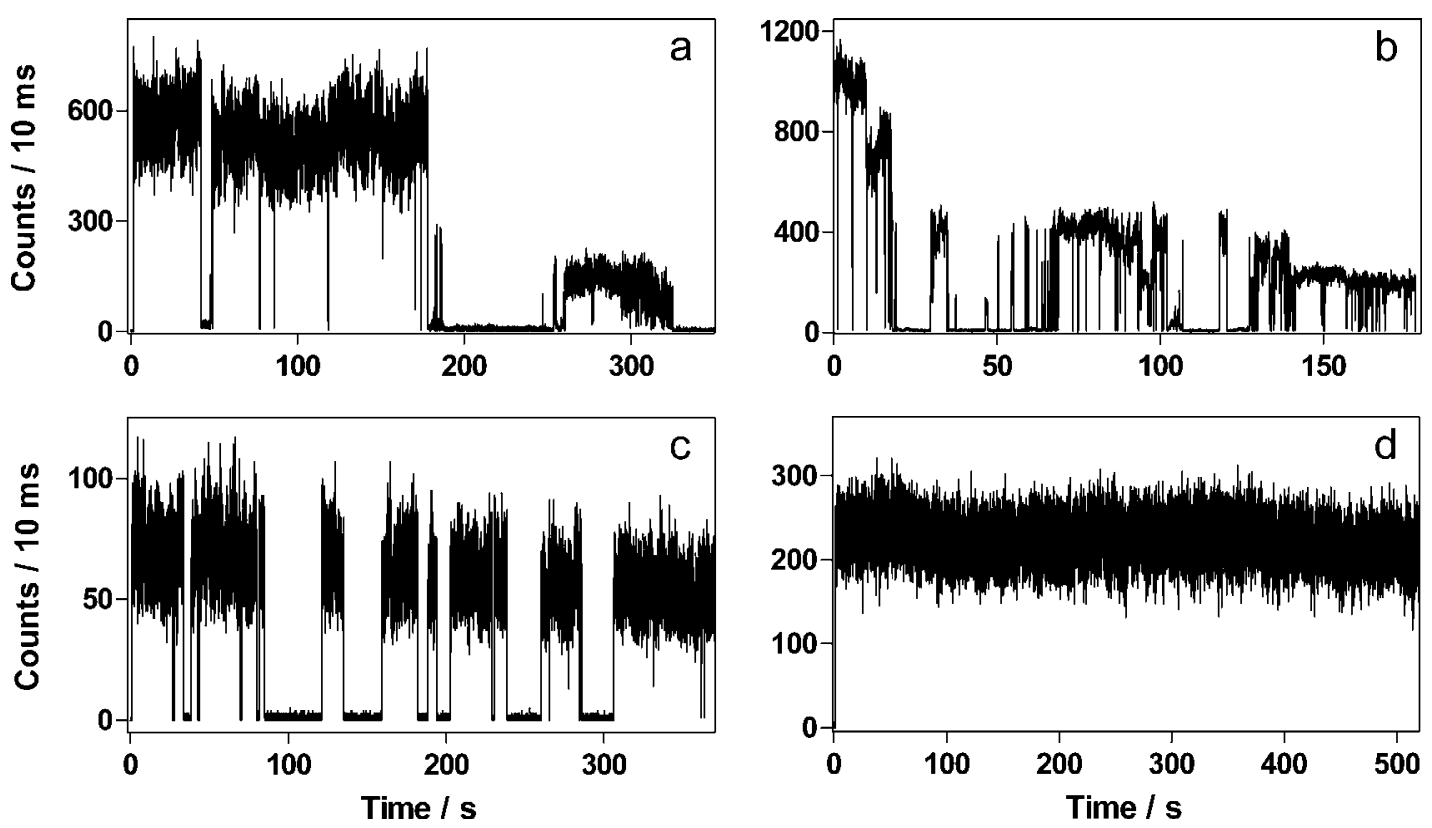

Figure 10. Single-molecule intensity traces of $\mathbf{1}$ (a), $\mathbf{2}$ (b), and 3 (c) showing rich on-off dynamics and of model compound 4 (d).

noting that blinking was observed under both pulsed and continuous wave excitation conditions. A detailed characterization of such on-off dynamics and the factors influencing it will be published elsewhere. ${ }^{55}$ The high photostability of these multichromophores allows measurement times for individual molecules of over $1 \mathrm{~h}$ in some cases at the excitation intensities required for single-molecule spectroscopy. This property is of great interest in the study of long-term changes in the dynamics of these multichromophores.

\section{Conclusions}

Highly fluorescent PDI units have been successfully incorporated into multichromphores with well-defined geometries via ethynylene bridges. The excited-state processes occurring after the absorption of light by these multichromophores have been characterized and compared to those of several model compounds. Our results show that the presence of the ethynylene units in the bay area of PDI can induce undesired electrontransfer processes. No such effects are present if the units are placed across the nodal plane provided by the imide nitrogen. These restrictions should be taken into account when building PDI dendritic architectures with ethynylene units for their potential use in photonic and electronic devices such as singlephoton emitters ${ }^{55}$ and light-emitting diodes. ${ }^{56}$ On the other hand, we have shown that these compounds are useful models in the study of competitive energy and electron transfer.

Acknowledgment. This work is supported by the Flemish Ministry of Education (GOA01/2) and the IAP-V-03 program. C.F. thanks the Institute for Nanoscale Physics and Chemistry (K.U. Leuven) for a postdoctoral fellowship. We thank Mr. P. Dedecker, Ms. A. Stefan, and Dr. R.A.L Vallée for assistance in TCSPC and single-molecule spectroscopy. Financial support by the Deutsche Forschungsgemeinschaft (SFB 625) and BASF AG is gratefully acknowledged.

Supporting Information Available: Detailed experimental procedures on synthesis and compound characterization, absorption and emission spectra of all compounds in THF, structure of compound PDI0, and femstosecond transient absorption spectrum of $\mathbf{2}$ in THF. This material is available free of charge via the Internet at http://pubs.acs.org.

\section{References and Notes}

(1) Balzani, V. Tetrahedron 1992, 48, 10443-10514

(2) Armaroli, N. Photochem. Photobiol. Sci. 2003, 2, 73-87.

(3) Cotlet, M.; Hofkens, J.; Habuchi, S.; Dirix, G.; Van Guyse, M.; Michiels, J.; Vanderleyden, J.; De Schryver, F. C. Proc. Natl. Acad. Sci. U.S.A. 2001, 98, 14398-14403.

(4) Bopp, M. A.; Jia, Y. W.; Li, L. Q.; Cogdell, R. J.; Hochstrasser, R. M. Proc. Natl. Acad. Sci. U.S.A. 1997, 94, 10630-10635.

(5) Wurthner, F. Chem. Commun. 2004, 1564-1579.

(6) Herrmann, A.; Weil, T.; Sinigersky, V.; Wiesler, U. M.; Vosch, T.; Hofkens, J.; De Schryver, F. C.; Mullen, K. Chem.-Eur. J. 2001, 7, $4844-4853$.

(7) Hofkens, J.; Maus, M.; Gensch, T.; Vosch, T.; Cotlet, M.; Kohn, F.; Herrmann, A.; Mullen, K.; De Schryver, F. J. Am. Chem. Soc. 2000, $122,9278-9288$.

(8) De Schryver, F. C.; Vosch, T.; Cotlet, M.; Van der Auweraer, M.; Mullen, K.; Hofkens, J. Acc. Chem. Res. 2005, 38, 514-22.

(9) Langhals, H. Helv. Chim. Acta 2005, 88, 1309-1343.

(10) Rybtchinski, B.; Sinks, L. E.; Wasielewski, M. R. J. Am. Chem. Soc. 2004, 126, 12268-12269.

(11) Sinks, L. E.; Rybtchinski, B.; Iimura, M.; Jones, B. A.; Goshe, A. J.; Zuo, X. B.; Tiede, D. M.; Li, X. Y.; Wasielewski, M. R. Chem. Mater. 2005, 17, 6295-6303.

(12) Serin, J. M.; Brousmiche, D. W.; Frechet, J. M. J. Chem. Commun. 2002, 2605-2607.

(13) Cotlet, M.; Masuo, S.; Lor, M.; Fron, E.; Van der Auweraer, M.; Mullen, K.; Hofkens, J.; De Schryver, F. Angew. Chem., Int. Ed. 2004, 43, 6116-6120.

(14) Cotlet, M.; Masuo, S.; Luo, G. B.; Hofkens, J.; Van der Auweraer, M.; Verhoeven, J.; Mullen, K.; Xie, X. L. S.; De, Schryver, F. Proc. Natl. Acad. Sci. U.S.A. 2004, 101, 14343-8.

(15) Holman, M. W.; Liu, R. C.; Zang, L.; Yan, P.; DiBenedetto, S. A.; Bowers, R. D.; Adams, D. M. J. Am. Chem. Soc. 2004, 126, 16126-33.

(16) Liu, R. C.; Holman, M. W.; Zang, L.; Adams, D. M. J. Phys. Chem. A 2003, 107, 6522-6526.

(17) Hoogenboom, J. P.; van Dijk, E. M. H. P.; Hernando, J.; van Hulst, N. F.; Garcia-Parajo, M. F. Phys. Rev. Lett. 2005, 95, 097401.

(18) Lee, S. K.; Zu, Y. B.; Herrmann, A.; Geerts, Y.; Mullen, K.; Bard, A. J. J. Am. Chem. Soc. 1999, 121, 3513-3520.

(19) Zhao, Y. Y.; Wasielewski, M. R. Tetrahedron Lett. 1999, 40, 70477050 .

(20) Bell, T. D. M.; Habuchi, S.; Masuo, S.; Osterling, I.; Mullen, K.; Tinnefeld, P.; Sauer, M.; van der Auweraer, M.; Hofkens, J.; De Schryver, F. C. Aust. J. Chem. 2004, 57, 1169-1173.

(21) Garcia-Parajo, M. F.; Hernando, J.; Mosteiro, G. S.; Hoogenboom, J. P.; van Dijk, E. M. P. H.; van Hulst, N. F. Chem. Phys. Chem. 2005, 6, 819-827. 
(22) Grimsdale, A. C.; Vosch, T.; Lor, M.; Cotlet, M.; Habuchi, S.; Hofkens, J.; De Schryver, F. C.; Mullen, K. J. Lumin. 2005, 111, 239253.

(23) Zhang, H.; Grim, P. C. M.; Foubert, P.; Vosch, T.; Vanoppen, P.; Wiesler, U. M.; Berresheim, A. J.; Mullen, K.; De Schryver, F. C. Langmuir 2000, 16, 9009-9014.

(24) Vosch, T.; Cotlet, M.; Hofkens, J.; Van der Biest, K.; Lor, M.; Weston, K.; Tinnefeld, P.; Sauer, M.; Latterini, L.; Mullen, K.; De Schryver, F. C. J. Phys. Chem. A 2003, 107, 6920-6931.

(25) Vosch, T.; Hofkens, J.; Cotlet, M.; Kohn, F.; Fujiwara, H.; Gronheid, R.; Van Der Biest, K.; Weil, T.; Herrmann, A.; Mullen, K. Mukamel, S.; Van der Auweraer, M.; De Schryver, F. C. Angew. Chem., Int. Ed. 2001, 40, 4643-4648.

(26) Takahashi, S.; Kuroyama, Y.; Sonogashira, K.; Hagihara, N. Synthesis 1980, 627-630.

(27) Sonogashira, K.; Tohda, Y.; Hagihara, N. Tetrahedron Lett. 1975 $4467-4470$

(28) Narayanan, V.; Sankarararnan, S.; Hopf, H. Eur. J. Org. Chem. 2005, 2740-2746.

(29) Moore, J. S.; Xu, Z. F. Macromolecules 1991, 24, 5893-5894.

(30) Moore, J. S. Acc. Chem. Res. 1997, 30, 402-413.

(31) Magde, D.; Brannon, J. H.; Cremers, T. L.; Olmsted, J. J. Phys. Chem. 1979, 83, 696-699.

(32) Maus, M.; Rousseau, E.; Cotlet, M.; Schweitzer, G.; Hofkens, J.; Van der Auweraer, M.; De Schryver, F. C.; Krueger, A. Rev. Sci. Instrum. 2001, 72, 36-40.

(33) Lakowicz, J. R. Principles of Fluorescence spectroscopy, 2nd ed.; Kluwer Academic: New York, 1999.

(34) Maus, M.; De, R.; Lor, M.; Weil, T.; Mitra, S.; Wiesler, U.; Herrmann, A.; Hofkens, J.; Vosch, T.; Mullen, K.; De Schryver, F. C. J. Am. Chem. Soc. 2001, 123, 7668-7676.

(35) Schweitzer, G.; Xu, L.; Craig, B.; DeSchryver, F. C. Opt. Commun. 1997, 142, 283-288.

(36) Eilingsfeld, H.; Patsch, M. Ger. Offen. BASF AG Germany 1976, $D E 2519790$ (p 9).

(37) Qu, J. Q.; Pschirer, N. G.; Liu, D. J.; Stefan, A.; De Schryver, F. C.; Mullen, K. Chem.-Eur. J. 2004, 10, 528-537.

(38) Corbet, J. P.; Mignani, G. Chem. Rev. 2006, 106, 2651-2710.

(39) Hofkens, J.; Latterini, L.; De Belder, G.; Gensch, T.; Maus, M.; Vosch, T.; Karni, Y.; Schweitzer, G.; De Schryver, F. C.; Hermann, A.; Mullen, K. Chem. Phys. Lett. 1999, 304, 1-9.
(40) Lor, M.; Viaene, L.; Pilot, R.; Fron, E.; Jordens, S.; Schweitzer, G.; Weil, T.; Mullen, K.; Verhoeven, J.; Van der Auweraer, M.; De Schryver, F. C. J. Phys. Chem. B 2004, 108, 10721-10731.

(41) Maus, M.; Mitra, S.; Lor, M.; Hofkens, J.; Weil, T.; Herrmann, A.; Mullen, K.; De Schryver, F. C. J. Phys. Chem. A 2001, 105, 39613966.

(42) Belfield, K. D.; Bondar, M. V.; Przhonska, O. V.; Schafer, K. J. J. Photochem. Photobiol., A 2002, 151, 7-11.

(43) Förster, T. Discuss. Faraday Soc. 1959, 27, 7-17.

(44) Karni, Y.; Jordens, S.; De Belder, G.; Schweitzer, G.; Hofkens, J.; Gensch, T.; Maus, M.; De Schryver, F. C.; Hermann, A.; Mullen, K. Chem. Phys. Lett. 1999, 310, 73-78.

(45) Kaletas, B. K.; Dobrawa, R.; Sautter, A.; Wurthner, F.; Zimine, M.; De Cola, L.; Williams, R. M. J. Phys. Chem. A 2004, 108, 19001909.

(46) Kircher, T.; Lohmannsroben, H. G. Phys. Chem. Chem. Phys. 1999, 1, 3987-3992.

(47) Ford, W.; Hiratsuka, H.; Kamat, P. V. J. Phys. Chem. 1989, 93, $6692-6696$

(48) Shida, T. Electronic Absorption Spectra of Radical Ions; Elsevier: Amsterdam, 1988.

(49) Schweitzer, G.; Gronheid, R.; Jordens, S.; Lor, M.; De Belder, G.; Weil, T.; Reuther, E.; Mullen, M.; De, Schryver, F. C. J. Phys. Chem. A 2003, 107, 3199-3207.

(50) Larumbe, D.; Moreno, M.; Gallardo, I.; Bertran, J.; Andrieux, C. P. J. Chem. Soc., Perkin Trans. 2 1991, 1437-1443.

(51) Marcoux, L. S.; Adams, R. N.; Feldberg, S. W. J. Phys. Chem. 1969, 73, 2611.

(52) Weller, A. Z. Phys. Chem. 1982, 133, 93-98.

(53) van Ramesdonk, H.; Vos, M.; Verhoeven, J.; Möhlmann, G.; Tissink, N.; Meesen, A. Polymer 1987, 28, 951-956.

(54) McGlynn, S. P.; Azumi, T.; Kinoashita, M. Molecular Spectroscopy of the Triplet State; Prentice Hall: Englewood Cliffs, NJ, 1969; pp 289307.

(55) Sliwa, M.; Flors, C.; Oesterling, I.; Hotta, J.; Mullen, K.; de Schryver, F. C.; Hofkens, J. J. Phys. Condens. Mater., in press.

(56) Qu, J. Q.; Zhang, J. Y.; Grimsdale, A. C.; Mullen, K.; Jaiser, F.; Yang, X. H.; Neher, D. Macromolecules 2004, 37, 8297-8306. 